\title{
Fraseología con nombre propio en el Diccionario de americanismos de la ASALE*
}

\author{
Phraseology with proper names in the Diccionario \\ de americanismos from the ASALE
}

\author{
Encarnación Tabares Plasencia \\ Universität Leipzig, Alemania \\ tabares@uni-leipzig.de
}

ORCID iD: https://orcid.org/0000-0003-2491-1901

\begin{abstract}
RESUMEN: En el presente trabajo se realiza un análisis de la fraseología con nombre propio (NP) contenida en el Diccionario de americanismos (DA) de la ASALE. En primer lugar, se ofrece una descripción somera de la obra y del fenómeno de la lexicalización, como requisito para la inclusión del nombre propio en el diccionario y característica de las unidades fraseológicas (UF); en segundo lugar, se especifican las pautas metodológicas para la extracción y estudio de las UF con NP. En tercer y último lugar se muestran algunos resultados obtenidos del análisis; concretamente, en relación con las UF con antropónimo por ser las más numerosas del grupo.
\end{abstract}

Palabras clave: Fraseología, nombre propio, antropónimos, Diccionario de americanismos.

ABSTRACT: In this paper we present an analysis of the phraseology with proper names (PN), wich can be found in the Diccionario de americanismos (DA). First, we offer a short description of the dictionary and of the lexicalization phenomenon as prerequisite for the inclusion of proper names in the dictionary and characteristic feature of the phraseologic units (PU). Second, we specify the methodologic rules for the extraction and the study of PU with PN. Third, we show some of the obtained results, specifically in relation with the UF with anthroponyms, as they are the most numerous in the group.

Keywords: Phraseology, proper names, anthroponyms, Diccionario de americanismos.

* Este trabajo es resultado del proyecto de investigación Los desarrollos semántico-lingüísticos del nombre propio en español: adjetivos de relación, hipocorísticos y lexicalizaciones, financiado por el Ministerio de Ciencia e Innovación de España ( ${ }^{\circ}$ de referencia FF2014-58260) entre los años 2015 y 2017. 


\section{INTRODUCCIÓN}

En el marco del proyecto de investigación Los desarrollos semántico-lingüísticos del nombre propio en español: adjetivos de relación, hipocorísticos y lexicalizaciones nos hemos dedicado, entre otras labores, a la extracción y análisis de todos los fenómenos lingüísticos relacionados con el nombre propio en español (creación de derivados, lexicalizaciones, etc.) ${ }^{1}$ en un corpus amplio de diccionarios y otras fuentes lexicográficas o de diferente naturaleza.

Una obra que nos ha proporcionado datos de gran interés ha sido el Diccionario de Americanismos (DA) de la Asociación de Academias de las Lengua Española (ASALE) (2010), una obra importante, no solo por su volumen de páginas y el número de entradas que recoge (70.000 con 120.000 acepciones) $)^{2}$, sino por la técnica lexicográfica empleada, producto de la nueva política lingüística panhispánica. Precisamente, el hecho de se trate de un diccionario descriptivo y no normativo, del uso real y actual de la lengua ha permitido el registro de préstamos (sobre todo, del inglés); pero también de neologismos derivativos (pinochetismo, antioquenada) y lexicalizaciones (en diferente grado) provenientes, en muchos casos, de nombres propios (de nombres de pila o apellidos, de marcas o de siglas; cfr. al respecto Almansa Ibáñez, 2014: 39 y Bravo García, 2015); e, incluso, algunos casos de apropiación de nombres propios con finalidad eufemística.

En esta contribución presentaremos una clasificación de las unidades fraseológicas del $D A$ procedentes de o que contengan nombre propio ${ }^{3}$ y valorare-

\footnotetext{
${ }^{1}$ Cfr., por ejemplo, las obras de Morera (2015, 2017a, 2017b), García Padrón (2016 y 2019), García Padrón y Batista (2018), Batista y García Padrón (2018), donde se detallan otros trabajos relacionados con el tema, los antecedentes de esta línea de investigación y el estado de la cuestión sobre la deonomástica del español. Muy conocidos sobre este tema son los trabajos de las hermanas García Gallarín (1997) y de Bajo Pérez (2008).

${ }^{2}$ Mazzocchi (2015: 54) señala, en relación con la repercusión del DA: "En España e Hispanoamérica, por otra parte, la obra no ha dejado de suscitar atención, incluso abriendo el debate, a veces polémico".

${ }^{3}$ Desde Dionisio de Tracia hasta la actualidad (Langendonck 2007a) se considera al nombre propio como el nombre por antonomasia. Una definición generalmente aceptada del nombre propio es la de Langendonck (2007b: 87 y 116): "A proper name is a noun that denotes a unique entity at the level of established linguistic convention to make it psychosocially salient within a given basic level category [pragmatic]. The meaning of the name, if any, does not (or not any longer) determine its denotation [semantic]. An important formal reflex of this pragmatic-semantic characterization of names is their ability to appear in such close appositional constructions as the poet Burns, Fido the dog, the River Thames, or the City of London [syntactic]". Algunos de los autores que han estudiado el nombre propio en relación con la fraseología en español y alemán, ordenados alfabéticamente, son: Batista y García Padrón (2018), Calero Fernández (1992), Földes (1984-1985), Häcki Buhofer (1995), Iglesias Ovejero (1999 y 2015), Lončar (2014), Nazarov y Bragança (2014) y Ripollés (1999). Y, por supuesto, son muy sugerentes los estudios antiguos de Montoto (1912).
} 
mos los resultados parciales obtenidos. Antes de comenzar, hablaremos siquiera mínimamente del fenómeno de la lexicalización, que es el que ha permitido la inclusión de muchas de estas unidades en la obra y que ha constituido uno de los pilares sobre los que se ha fundado el estudio de la fraseología ${ }^{4}$.

\section{EL FENÓMENO DE LA LEXICALIZACIÓN}

En la "Guía del consultor" del propio DA (2010: XXXII) puede leerse el tipo de unidades que tienen cabida en la obra, a saber:

a) lexemas autóctonos de América y sus derivados,

b) creaciones originales americanas,

c) criollismos morfológicos,

d) lexemas de procedencia española con cambio de especificación en el contenido semántico,

e) arcaísmos españoles vivos en América,

f) lexemas procedentes de otras lenguas tanto antiguos en el español americano como recientes.

Así mismo en la siguiente página (DA, 2010: XIII) se nos señala que "no se incluyen en la macroestructura del diccionario de americanismos ni acrónimos, ni nombres propios, a menos que estén lexicalizados". Y más adelante (ibíd.) se continúa: "Tampoco da entrada en sus páginas a refranes, pero sí a frases proverbiales". En el propio diccionario se emplea, pues, la lexicalización como criterio para la inclusión de entradas en el diccionario pero, sin embargo, no se explicita qué se entiende por este fenómeno. Los conceptos de lexicalización y de gramaticalización - muy relacionado con aquel ${ }^{5}$ - han sido objeto de mu-

${ }^{4}$ Mucho se ha escrito modernamente sobre esta cuestión desde el pionero estudio de Bosque (1982) hasta las aproximaciones cognitivas de Moreno Cabrera (1998 y 2013) y Elvira (2006, 2012 y 2015).

${ }^{5}$ Castro Zapata (2013: 66), con acierto indica: "Concebimos ambos procesos [gramaticalización y lexicalización] como un mismo vector con dos direcciones en el que la unidad lingüística (ya sea léxica o gramatical) experimenta cambios. Si estos van situándose más cerca de lo gramatical a través de la pérdida de su carga semántica, se hablará de gramaticalización. Si, por el contrario, el péndulo se decanta hacia la adquisición de un mayor contenido semántico estaremos ante una lexicalización [...]. Así, toda unidad (A) va a partir de una situación inicial, un origen (categoría, clase, rasgos...) dentro del vector (contexto histórico, discursivo, sintáctico, etc.). Esa posición irá variando a través de las necesidades comunicativas de los hablantes en cada momento, de la historia, de las posibilidades gramaticales y léxicas de la pieza (abstracción o concreción semántica) y se irá perfilando hacia una dirección concreta (gramaticalización o lexicalización)". Asimismo, Buenafuentes de la Mata y Sánchez Lancis (2012: 155) señalan algunos rasgos comunes de ambos fenómenos: "En primer lugar, porque en determinadas circunstancias [gramaticalización y lexicalización] pueden llegar a interactuar y, en segundo lugar, porque son manifestaciones del cambio lingüístico y, como tales, presentan muchas características en común: son procesos gra- 
chas discusiones y replanteamientos, al tratarse de fenómenos lingüísticos generales, desde que aparecieron por primera vez en las obras de Bally (1932) y Meillet (1912), respectivamente. Específicamente, la lexicalización entendida como la transformación o el paso de un elemento gramatical en uno léxico o de uno léxico en uno más léxico (cfr. Buenafuentes de la Mata y Sánchez Lancis 2012: 155), según los diferentes autores que han tratado la cuestión (Lyons, 1977; Faitelson-Weiser, 1980; Bauer 1983; Talmy, 1985; Brinton, 2000; Lehmann, 2003; Company, 2003; Brinton y Traugott, 2005; Buenafuentes de la Mata, 2007, entre otros) puede verse, como ha resumido Aranda Gutiérrez (2010: 13), desde cuatro puntos de vista: a) como un proceso de entrada de una unidad en el léxico, esto es, como una forma de incremento léxico adoptado a partir de la formación de palabras (Faitelson-Weiser, 1980; Company, 2003); b) la lexicalización como pérdida de la productividad gramatical debida a un proceso de fosilización (Lyons, 1977) o de institucionalización (Bauer, 1983); c) la lexicalización como desgramaticalización; d) lexicalización como proceso de transferencia de la dimensión sintagmática a la paradigmática (Blasco Mateo, 2002: 35).

En relación con el nombre propio en general, compartimos la idea expresada por García Padrón (2016) de que la lexicalización supone la conversión del nombre propio en común ${ }^{6}$ y de que esta solo puede darse cuando se produce su desgramaticalización, bien por desarrollo derivativo (franciscana 'tipo de sandalia', 'variedad de delfín', bien porque se haya perdido un valor gramatical en favor de uno léxico (Osnaburgo ${ }^{7}>$ osnaburgo 'tipo de tejido' (cf. también en torno al concepto de lexicalización de nombres propios, Herrero Ruiz de Loizaga (2002) y Morera (2017b) en cuanto a la lexicalización de nombres propios como fuente de raíces léxicas).

La lexicalización en el ámbito de la fraseología tampoco ha estado exenta de polémica — el disenso se ha desarrollado incluso con mayor virulencia-. Algunos autores la relacionan igualmente con la gramaticalización. Montoro del Arco (2006: 48) considera que ambos procesos pueden estar detrás de la polémica idiomaticidad, propiedad que suele predicarse de las UF. La idiomaticidad, que

duales que, por tanto, se desarrollan en un continuum; unidireccionales, es decir, irreversibles; pueden producir modificaciones de carácter morfofonológico, y ambos implican un cambio semántico." Por su parte, y desde el punto de vista cognitivo, Elvira (2015: cap. 8) examina el fenómeno de la lexicalización como propio del dominio cognitivo, frente a la gramaticalización, que operaría en el dominio semántico. En la lexicalización se produciría, por tanto, un desplazamiento del procesamiento hasta la memoria; en la gramaticalización, por el contrario, el movimiento iría desde lo léxico hasta lo funcional.

${ }^{6}$ Cfr. Migliorini (1968 [1927]) uno de los trabajos pioneros sobre el análisis de la conversión del nombre propio en común.

${ }^{7}$ Adaptación al castellano del exónimo inglés Osnaburg (Osnabrück). 
algunos linguistas han relacionado con la no composicionalidad del significado de la expresión fraseológica, otros con un grado de especialización semántica tal que derivaría en la opacidad de aquella, y otros, en esta misma línea, con un significado traslaticio, ha sido considerada por algunos estudiosos como el mencionado autor como el producto, desde el punto de vista sincrónico, del proceso diacrónico de la lexicalización, que puede llegar incluso a la gramaticalización. En este mismo sentido se expresa Echenique Elizondo (2010) al hablar de las locuciones adverbiales, prepositivas y conjuntivas del español:

Este proceso mediante el cual una palabra común va siendo desplazada del uso diario por razones de cambio léxico, en tanto queda fijada idiomáticamente en una unidad fraseológica determinada, participa al mismo tiempo de los efectos caracterizadores de lo que entendemos por lexicalización como de la gramaticalización. De hecho, las locuciones adverbiales, al igual que otras locuciones prepositivas y conjuntivas muy frecuentes en español (y en otras lenguas románicas), pueden ser el resultado de un cruce entre un proceso de lexicalización y otro de gramaticalización [...]. Mientras la lexicalización parte de la sintaxis o de la morfología y concluye en el léxico (sería el caso de adiós en la lengua actual), la gramaticalización afecta a piezas léxicas o a sintagmas que pierden parte de su contenido semántico y características distintivas propias de los elementos de relación, llegando en el caso extremo a convertirse en categorías funcionales [...]. En casos como en un santiamén se combinan los dos procesos: de lexicalización en santiamén $(<[$ Spiritu $]$ sancti amén) y de gramaticalización en el conjunto de la unidad.

\section{EL NOMBRE PROPIO EN EL $D A$}

Para ofrecer un análisis lo más exhaustivo posible de la presencia de los nombres propios en el $D A$, hemos llevado a cabo los siguientes pasos:

1. Realizamos, en primer lugar, un vaciado manual de la versión impresa de la obra. Consideramos que esta era la mejor manera de proceder, dado que la versión digital solo permite búsquedas individualizadas y que el escaneo de toda la obra y su conversión en texto plano o compatible para el empleo de programas que ofrecen listas de palabras no suponía una ventaja temporal sino todo lo contrario. En este sentido, ha de tenerse en cuenta que los datos que ofrecemos revisten cierto carácter provisional, pues, en el futuro, pensamos en llevar a cabo otro vaciado con el fin de evitar que hayamos pasado por alto unidades de interés para nuestra investigación.

2. Una vez efectuada la extracción, cuyo principio rector fue aislar unidades, ya fueran mono- o pluriverbales, que contuvieran como mínimo un nombre propio en cualquiera de sus modalidades, realizamos una clasificación basada, por un lado, en el tipo de nombre propio (antropónimos, topónimos, nombres y 
marcas comerciales, siglas y acrónimos) ${ }^{8} ; \mathrm{y}$, por otro, en formas derivadas y no derivadas 9 . Aparte, establecimos la categoría de fraseologismos, donde, a su vez, se elaboró una subclasificación dependiendo del tipo de nombre propio o derivado de nombre propio que estos contuvieran y a la que en breve se hará alusión. En total, el número de unidades totales con nombre propio es de 823, cuya distribución se presenta en la tabla 1 .

\begin{tabular}{|l|c|c|c|c|c|c|c|c|}
\hline UNIDADES & Antr. & Top. & NM & NOI & SA & Derivados & UF & Total \\
\hline NúMERO & 204 & 47 & 72 & 0 & 0 & 291 & 209 & 823 \\
\hline
\end{tabular}

TABLA 1.-Número total y por grupos de unidades con nombre propio. Abreviaturas: Antr. (antropónimos), Top. (topónimos), NM (nombres de marcas), NOI (nombres de organizaciones e instituciones), SA (siglas y acrónimos de nombres propios), UF (unidades fraseológicas).

3. Tras las clasificaciones, el siguiente paso fue determinar los campos conceptuales más importantes en que podían insertarse las unidades extraídas, para, seguidamente, establecer el procedimiento (extensión metafórica, metonímica, paranomasias, etc.) que ha dado lugar a la conversión de un nombre propio en un epónimo. Igualmente, nos interesaba mostrar cuál o cuáles son las referencias culturales concretas que subyacen a dicha conversión, en los supuestos en los pueda determinarse. En el caso de las UF, aparte de las referencias culturales subyacentes, queríamos analizar qué tipos de estructuras sintácticas son las más productivas, qué funciones cumple el nombre propio en ellas, así como sus valores pragmáticos.

\section{LAS UNIDADES FRASEOLÓGICAS CON NOMBRE PROPIO (NP) EN EL DA}

\subsection{Consideraciones generales}

Como primera consideración general aplicable a las unidades fraseológicas, pero también al resto de los grupos estudiados, es que no se han considerado en el recuento las variantes gráficas o fónico-gráficas de las voces y expresiones, a menos que las variantes de este tipo implicaran acepciones diferentes (cuáquer frente quáker o rockola frente a rocola, por ejemplo). Se han incluido en el

\footnotetext{
${ }^{8}$ A la tipología o clasificación de los distintos nombres propios dedica Langendonck (2007b: 183-255) todo el tercer capítulo de su obra más conocida. En español pueden consultarse los intentos de Iglesias Ovejero (1991) y Bajo Pérez (2008: 15-59).

${ }^{9}$ Cfr., entre otros, sobre la derivación del nombre propio: Schweickard (1992 y 1995), Lisyová (2005), Reinhardt (2010), Malá (2014), García Gallarín (2017).
} 
cómputo las variantes formales ${ }^{10}$, puesto que constituían muchas veces variación geográfica $\mathrm{y}$, de esta forma, hemos querido dejar constancia de la misma por las implicaciones lingüísticas o culturales que pudieran tener. Además, algunas estructuras idénticas o casi idénticas, presentan, en el $D A$, diferencias de sentido. Así, por ejemplo, en dar lo mismo Chana que Juana y dar lo mismo Juana que Chana estructuralmente idénticas, con tan solo un cambio en el orden de los antropónimos, puede verse que, mientras la primera expresión significa 'dar lo mismo una cosa que otra' en prácticamente toda América Central y Chile, la segunda se encuentra especializada en el ámbito delincuencial como 'matar a una persona' en Honduras ${ }^{11}$.

En este punto, es necesario aclarar igualmente los siguientes aspectos:

a) El número de UF con NP que se presenta en la tabla 1 procede del recuento de unidades consignadas y catalogadas en el DA como locuciones, frases proverbiales y fórmulas, esto es, los elementos que, de acuerdo con la moderna disciplina fraseológica en el mundo hispánico, fundamentalmente a partir del tratado clásico de Corpas Pastor (1996), se vienen considerando fraseológicas. Ello no obsta para que se hayan extraído otras unidades con nombre propio que, a nuestro entender, podrían entrar dentro de lo fraseológico pero que no aparecen catalogadas en los términos expuestos (p. ej. hora peruana, hora alemana, etc.). En muchos casos, las hemos incluido en los otros grupos de unidades constituidas con NP y, en un estudio posterior, se analizarán y reclasificarán conjuntamente con las extraídas para este trabajo.

b) La clasificación y el cómputo por subgrupos de unidades que se pueden ver en las tablas recogidas más adelante obedecen a la nomenclatura empleada en el $D A$. Además, una misma unidad ha podido ser considerada más de una vez en las estadísticas por subtipos de expresión, en atención al criterio funcional que se emplea en el $D A$ para etiquetar las expresiones. En ello se sigue la tendencia apuntada por la Nueva gramática de la lengua española (Real Academia Española y ASALE, 2009: 54), donde se señala que la clase gramatical que puedan tener las locuciones no tiene que estar determinada por su estructura sintáctica, de forma tal que una locución sustantiva, adjetival o adverbial se catalogará como tal por la función que pueda desempeñar, pero no porque tenga la estructura sintáctica de un grupo nominal, adjetival o adverbial. Así, por ejemplo, expresiones como juan bobo, juan caballo o María palito se registran como locuciones sustantivas y adjetivas o en pampers, que, a pesar de su es-

${ }^{10}$ No nos ocuparemos de la variación fraseológica por falta de espacio y por no ser el asunto central de este trabajo. Remitimos a Sinner y Tabares Plasencia (2016), donde se ofrece una panorámica de los estudios sobre la variación en fraseología.

${ }^{11}$ Habrá que hacer un rastreo más exhaustivo de la expresión para corroborar el sentido apuntado para Honduras. Por el momento, las búsquedas en los corpus de referencia académicos CREA y CORPES XXI no han confirmado esta acepción. 
tructura, se cataloga como locución adjetiva o como turco en la neblina que se cataloga como locución adjetiva y adverbial al mismo tiempo.

c) En cuanto a la división por tipo de nombre propio (antropónimo, topónimo, nombre de marca), es preciso indicar que se ha seguido el criterio de la referencia a la que el NP hace, esto es, en los topónimos deantroponímicos (siquiera inventados como San Nicolás del Peladero) se ha atendido a la designación de lugar y no al antropónimo: no ir a ningún Pereira (donde el apellido Pereira ha servido para denominar un municipio en el departamento colombiano de Risaralda) o entre Lucas y Juan Mejía (donde estos antropónimos se refieren a dos parajes en la provincia dominicana de El Seibo).

\subsection{Tipos de UF y su conceptualización en el DA. Análisis crítico}

En la "Guía del Consultor", en el apartado denominado "Macroestructura del Diccionario de Americanismos" (DA, 2010: XXXIII-XXXIV), se establece qué tipo de unidades lexémicas se recogen en la obra (Tabla 2).

\begin{tabular}{|l|l|}
\hline \multicolumn{1}{|c|}{ UIPO } & \multicolumn{1}{|c|}{ CARIDADES LEXÉMICAS EN EL DA } \\
\hline LEXEMAS SIMPLES & Constan de una sola UL \\
\hline LEXEMAS COMPUESTOS & $\begin{array}{l}\text { Resultan de la unión (gráfica) de dos o más palabras (cuida- } \\
\text { palos) }\end{array}$ \\
\hline FÓRMULAS & $\begin{array}{l}\text { UL no susceptibles o con pocas posibilidades de flexión con } \\
\text { valor de enunciado retórico con diferentes funciones discur- } \\
\text { sivas. Serían de tres tipos: de tratamiento (angú), de comuni- } \\
\text { cación (aló) y léxicas (dizque) }\end{array}$ \\
\hline LEXEMAS COMPLEJOS & $\begin{array}{l}\text { Combinación léxica cuyo contenido sería la suma de los sig- } \\
\text { nificados de los elementos integrantes (composicionalidad) } \\
\text { (agua agria1) }\end{array}$ \\
\hline LOCUCIONES & $\begin{array}{l}\text { Combinación léxica caracterizada, desde el p. v. semántico, por } \\
\text { no disponer de un significado composicional, esto es, a decir } \\
\text { de los autores, su significado es total o parcialmente metafó- } \\
\text { rico; desde el p. v. sintáctico por corresponder a una clase de } \\
\text { palabras y desempeñar las funciones que le son propias a esa } \\
\text { clase de palabras en la oración simple. Serían de ocho tipos: } \\
\text { sustantivas - indio viejo; adjetivas - boca floja; verbales - co- } \\
\text { merse un garrón; adverbiales - como jefe, - a; interjectivas }\end{array}$ \\
\hline
\end{tabular}

12 Tal como aparece explicado, resulta difícil creer en esta categoría de lexemas complejos, porque no siempre su significado es la suma del significado de sus componentes. 


\begin{tabular}{|l|l|}
\hline & $\begin{array}{l}\text { - a la macana. También existirían, en menor medida, las pre- } \\
\text { posicionales, las pronominales y las conjuntivas }{ }^{13} \text {. }\end{array}$ \\
\hline FRASES PROVERBIALES & $\begin{array}{l}\text { Desde el p. v. semántico se caracterizarían por la no compo- } \\
\text { sicionalidad de su significado y sintácticamente por no des- } \\
\text { empeñar funciones sintácticas propias de una clase de pala- } \\
\text { bras, pues son independientes: iqué linda la jaula y qué feo } \\
\text { el pichón! }\end{array}$ \\
\hline
\end{tabular}

TABLA 2.-Tipos de unidades lexémicas del $D A$ con aclaración.

Adelantaremos que, evidentemente, en ningún momento se emplea el término fraseología u otros afines (unidad fraseológica, fraseologismo, etc.), y, explícitamente, se señala que "no se da entrada a colocaciones porque no son unidades lexicalizadas y porque su sentido es más que obvio (aplauso atronador)" (DA, 2010: XXXIII). Resulta poco satisfactoria la aclaración que se presenta para despachar a las colocaciones, esto es, parecen discutibles y expuestos con bastante superficialidad los criterios para no considerar a las colocaciones dignas de estar incluidas en el diccionario, sobre todo, si tenemos en cuenta que una parte de la bibliografía científica existente sobre este tipo de combinaciones de palabras sigue abogando por su registro en los diccionarios (Corpas Pastor, 1996; Castillo Carballo 2020; entre otros). No nos introduciremos en profundidad - pues ese no es el tema central de este trabajo - en la cuestión siempre polémica de las combinaciones léxicas y el diccionario, pero sí nos gustaría incentivar siquiera el debate de determinados puntos conflictivos en torno a la conceptualización y denominación de ciertas formaciones pluriverbales dado que, como ya hemos señalado más arriba, nuestra intención en el futuro es ofrecer un análisis y reclasificación o reubicación de este tipo de expresiones con NP del DA. Así, volviendo a las colocaciones, ¿qué quieren decir los autores del diccionario con que no están lexicalizadas? Ya sabemos que la lexicalización es un proceso gradual y graduable que podría predicarse también de las colocaciones (Lipka, 1983; Wotjak, 1998a; Corpas, 1996; entre otros muchos), esto es, no necesariamente tienen que carecer de idiomaticidad por lo que su significado tampoco tiene que ser "obvio" (entendemos que con obvio se refieren los autores del DA que es composicional $)^{14}$. Pero si los hechos para quedar fuera del diccionario son esos,

${ }^{13}$ Se seguiría, en este sentido, el mismo criterio de la RAE en su Diccionario esencial (2006), en el que se establece el mismo número y tipos de locuciones (cfr. García-Page, 2013: 256-257), a quien remitimos para un mejor conocimiento de la evolución del concepto y de los tipos de locución en la lexicografía académica.

${ }^{14}$ En la Nueva gramática, en relación con la diferencia entre compuestos sintagmáticos y locuciones se señala lo siguiente: "Las unidades máximamente transparentes en el sentido de que su significado se puede deducir de los significados de sus componentes son las sintácticas, mientras 
¿por qué encontramos unidades como Echar(se) y Tirarse un samuel, adscritos al grupo de las locuciones verbales?; el NP ya se encuentra ya lexicalizado para Costa Rica como 'Acto de samuelear, observar.' (DA, s. v. samuel). Si acudimos a la entrada samuel, encontramos 'Observar un hombre en forma oculta o con disimulo las partes pudendas de una persona, en especial las de una mujer' (DA, s. v. samuelear). Por su parte, el $D L E$ (s. v. echar, acep. 25) señala que el verbo echar "junto con algunos nombres, tiene la significación de los verbos que se forman de ellos o la de otros equivalentes. Echar maldiciones, maldecir; echar suertes, sortear; echar un cigarro, fumarlo; echar un sueño, dormir; echar la siesta, sestear. Lo mismo cabría decir de Hacer panchos, consignada también como locución verbal (s. v. hacer), con el sentido, para México, de 'Tener un berrinche o montar un escándalo', cuando en la entrada pancho como primera acepción se lee " $M x$. Rabieta que causa escándalo o gran extrañeza". Siendo esto así, ¿no podría decirse que estas construcciones están más cerca de las colocaciones, o mejor, de las construcciones con verbo soporte? (cfr. Wotjak y Heine, 2005, entre otros trabajos). Otras unidades como Ser un Juan Bobo (República Dominicana), catalogada como locución verbal en el $D A$ (s. v. ser), ¿no sería más bien una de las llamadas colocaciones complejas (cfr. Koike, 2005) toda vez que la combinación nominal juan bobo se recoge como locución adjetiva con el sentido de 'persona tonta' si asumimos, de todas maneras, que juan bobo(s) se emplee con función adjetiva y no siempre en la locución verbal? Lo mismo ocurriría, a nuestro modo de ver, con la expresión, registrada para Honduras y El Salvador, Caerle ${ }^{15}$ (a alguien) martín callado 'castigar a alguien' (DA, s. v. caer), si no fuera por el hecho de que martín callado 'castigo que se da a un hijo por su mal comportamiento' no se consigna en el diccionario como locución sino como lexema complejo. Y, precisamente, la categoría de lexema complejo que se emplea en el $D A$, como se ha podido ver en la tabla 2, nos introduce en una cuestión de delimitación conceptual mucho mayor, y que permite sacar a colación la afirmación de Alvar Ezquerra (2003: 97, citado en Castillo Carballo, 2020) de que "las lexías complejas no tienen un tratamiento uniforme en todos los diccio-

que las más opacas suelen ser las locuciones. Los compuestos sintagmáticos suelen ser transparentes (ciudad dormitorio, decreto ley, relación madre-hija) sin bien algunos los son parcialmente (hombre rana, tren bala). La noción opuesta a la de composicionalidad es la de idiomaticidad" (Real Academia Española y Asociación de Academias de la Lengua Española, 2009: 743). En este sentido, uno de los motivos por los cuales García-Page (2008) rechaza la pertenencia de las colocaciones a la fraseología es porque considera que son unidades que forman parte de la sintaxis y carecen de idiomaticidad. Tampoco Bosque (2001) las considera parte de la fraseología sino como un fenómeno entre la sintaxis y el léxico.

${ }^{15}$ La combinación caer + sust. (objeto) con el significado de castigo y otras unidades léxicas de la misma clase semántica (pena, p.e.) es bastante frecuente. Así, de caerle a alguien un castigo, se registran más de 47000 ocurrencias en Google. Por su parte, caerle a alguien una pena tiene más 100000 ocurrencias en Google. 
narios de nuestra lengua, ni tan siquiera en el interior de una sola obra". El problema mencionado tiene ver con el grupo de las combinaciones léxicas nominales. Así pues, desechadas, al parecer, las colocaciones, los autores del DA apuntan que tendrán registro en la obra los lexemas compuestos, que aclaran, sin demasiado detalle, como el resultado de la unión de dos o más palabras. No se explica, sin embargo, qué se entiende por unión (pues no se menciona que sea gráfica), ni tampoco palabra. Pero, por el ejemplo que se ofrece, parecen estar refiriéndose a los compuestos léxicos u ortográficos. Más adelante alude a los citados lexemas complejos que opone a las locuciones (sustantivas) fundamentalmente por la composicionalidad o no composicionalidad de su significado respectivamente. Ambas serían combinaciones léxicas, pero si bien a las locuciones se les otorga un trato preferente, pues en el infralema no solo se las cataloga, sino que se les atribuye una categoría funcional, a los lexemas complejos solo se les otorga información gramatical. Realmente, se nos esconde por qué el $D A$ usa este término tan vago de lexema complejo, que, en principio, no excluiría a las locuciones, puesto que estas combinaciones son tan complejas como aquellos y, como acertadamente ha indicado Castillo Carballo (2020), en la Nueva gramática se ha tratado la cuestión y se ha ofrecido, con mayor o menor acierto, una postura en torno a la diferencia entre compuestos sintagmáticos y locuciones. Resumidamente, en la Nueva gramática (2009: 192), en la que participó también la ASALE, no se establece una delimitación neta entre compuesto y locución, sino que se habla de tres clases de compuestos: a) los univerbales o léxicos, caracterizados mediante propiedades formales, esto es, que se presentan como una unidad gráfica y acentual (agridulce, sacapuntas, etc.); b) los compuestos sintagmáticos, constituidos mediante la "yuxtaposición de palabras que conservan su propia independencia gráfica y acentual”, siendo que algunas pueden aparecer separadas mediante un guion (árabe-israelí, teórico-práctico, etc.) o sin él (casa biblioteca, cocina comedor, etc.); c) los compuestos sintácticos, considerados por autores como Val Álvaro (1999) como compuestos sintagmáticos, son conceptuados en la Nueva gramática como unidades de la fraseología y, por tanto, locuciones (media naranja, caballo de batalla, etc.). Como vemos, la cuestión se ha desarrollado en el seno de la Fraseología y de la Formación de Palabras, sobre todo, en torno a los llamados compuestos sintagmáticos, término acuñado, como todos sabemos, por Bustos Gisbert (1986). Precisamente, la distinción entre los compuestos sintagmáticos (de naturaleza nominal) y las locuciones nominales se ha convertido en una de las cuestiones más controvertidas tratadas por fraseólogos y morfólogos. El término locución, bastante añejo (cfr. Montoro del Arco, 2017), adquiere mayor relevancia a partir de Casares (1992 [1950]: 170). Pero ha sido, sobre todo, desde finales de los años noventa del pasado siglo cuando los investigadores han intentado establecer criterios lingüísticos para fijar la distinción entre esta categoría y la de los compuestos sintagmá- 
ticos, e igualmente entre estos y las colocaciones. Por cuestiones de espacio, hemos de dejar la discusión en este punto, pero remitimos a los trabajos de Pérez Vigaray (1996), Corpas Pastor (1996), Castillo Carballo (1998a y 1998b), Ruiz Gurillo (2002), García Page (2008a y 2012), Pérez Vigaray y Batista (2005), Montoro del Arco (2008) García Padrón y Batista (2010a y 2010b), donde se ha tratado in extenso esta compleja cuestión aún sin resolver en torno a las unidades pluriverbales nominales. Por nuestra parte, hemos querido plantear la asistematicidad con que estas unidades se han registrado en el $D A$ y la falta de adecuación a los criterios expuestos en la Nueva gramática o en los trabajos sobre la cuestión. Si no, ¿cómo es posible que martín callado se registre como lexema complejo, pero juan bobo como locución? Es cierto que la primera expresión tiene naturaleza denominativa, frente a la atributiva de la segunda, pero ambas son idiomáticas (incluso la segunda en menor grado que la primera). Algo parecido ocurre con isabel dormida 'combinado de bebidas alcohólicas', recogida como locución sustantiva e isabel segunda 'arbusto', catalogada como lexema complejo, o sangre de baco 'bebida que se obtiene de la fermentación de uvas silvestres'. ¿A qué grupo podemos adscribir las expresiones hora alemana, hora americana, hora peruana, hora boliviana, etc., unas referidas a momentos posteriores o tardíos y otras al momento puntual, pues parecen formar paradigmas pero poseen cierta idiomaticidad?

En cuanto a las fórmulas y frases proverbiales, también puede destacarse cierta asistematicidad en su registro ${ }^{16}$. En relación con las fórmulas, de las que se habla en el $D A$, hemos constatado el diferente tratamiento que reciben algunas formas como Sepa Moya (Chile) 'Se usa para dar a entender que no se sabe aquello de lo que se está hablando', registrado como fórmula; sin embargo, iSepa Judas! (Costa Rica, Nicaragua y Honduras), ¡Sepa Pancha! (México), ¡Sepa Juárez! (El Salvador), con el mismo sentido, como locuciones interjectivas. Otra cuestión digna de mención es el hecho de que, a pesar de que se mencionan tres tipos de fórmulas (de tratamiento, de comunicación y léxicas), esta información no se encuentra en la entrada, lo que contrasta con la información que se ofrece de las locuciones. En cuanto a las frases proverbiales, hay que señalar que, entre ellas, se hallan algunas unidades con una estructura clara de locución verbal. Como ejemplos quepan: Dejar como la chancha de tía Lacha (Nicaragua) 'Indica que alguien está bajo la responsabilidad de otra persona que no le proporciona los medios suficientes para la subsistencia', Hacer como Blas (que ya comiste y ya te vas) (Cuba, Puerto Rico, República Dominicana,Venezuela) 'Indica que

16 Sobre el tratamiento de las unidades fraseológicas y, especialmente, de las fórmulas en los diccionarios, cfr., entre otros autores: Tristá Pérez (1998), Gerd Wotjak (1998b), Barbara Wotjak (1998 y 2005), Ruiz Gurillo (2000), Castillo Carballo (2001), Déniz Hernández (2001), Zuluaga (2002), García-Page (2013) y Leiva Rojo (2015). 
alguien se marcha de un lugar de forma apresurada', Estar más apagado que el volcán Cosigüina (Nicaragua, Honduras) 'Indica que un hombre ha perdido su potencia sexual', No ir a ningún Pereira (Colombia Oriental) 'Indica que si algo se hace de forma perezosa y desinteresada no se logrará'.

Otro aspecto que cabría mencionar es la asistematicidad en la inclusión de información morfosintáctica, actancial, que permita una cabal intelección del fraseologismo. En algunas se constata cierta información (aunque no en la forma citativa). Consideramos que sería deseable que se recogiera más información sobre las posibles realizaciones de estas expresiones, esto es, si presentan restricciones transformacionales tanto morfosintácticas como semánticas. En el caso de las locuciones verbales (un buen número de las que aquí recogemos lo son), como ya ha propugnado Wotjak (1998b: 317) debería consignarse cuántos actantes intervienen y si se trata de actantes animados o no y su función sintáctica. Máxime, cuando el $D A$ ha dado al verbo de las locuciones verbales un papel preponderante, pues en el subapartado dedicado a la lematización de las unidades recogidas se señala $(D A, 2010: \mathrm{XXXVI})$ :

A diferencia de los diccionarios ad usum, las locuciones verbales van sublematizadas por el primer verbo (chupar(se) / medias), excepto si este tiene valor auxiliar, en cuyo caso se atiende al verbo principal. Si la locución puede ser utilizada con varios verbos, se le da entrada en la macroestructura por el uso más frecuente; el otro o los otros aparecerán como variantes o sinónimos.

Por lo demás, habría que mencionar posibles errores de marcación geográfica (vid. s. v. quilmes) o de procedencia de determinadas formas en el registro de las UF (vid. s. v. alka).

\section{Resultados}

\subsection{Datos generales}

Si se atiende a las cifras y porcentajes que se muestran infra, puede verse que el mayor número de UF con NP se corresponde con el de los antropónimos y sus derivados $(125,60 \%)$, dato que está en consonancia con el de unidades deantroponímicas que se registran en el DA. Con poco más de la mitad de las UF deantroponímicas se encuentran las detoponímicas (70, 33 \%). El grupo menos numeroso lo constituye el de UF con NM, que no supera el $10 \%$ (14). Como puede comprobarse en las tablas 3 y 4 , el tipo de UF más representado, en conjunto $(180,86 \%)$ y por grupos, es el de las locuciones: antropónimos y sus derivados $(102,59 \%)$; topónimos y sus derivados $(65,93 \%)$; nombres de marca y sus derivados $(12,93 \%)$. Esto se puede explicar por la reticencia de los dic- 
cionarios no fraseológicos a incluir fórmulas y frases proverbiales. Dicha reticencia está relacionada con la argumentación de Casares (1992 [1950]: 42-49), para el que los refranes no deben contenerse en el diccionario y las frases proverbiales solo en determinados supuestos, esto es, que es necesario analizarlas caso por caso. Entre las locuciones, y con gran diferencia, las más numerosas son las locuciones verbales: antropónimos y sus derivados $(61,59 \%)$, topónimos y sus derivados (43,66\%), NM y sus derivados $(11,84 \%)$ No obstante, también encontramos cierta representación de las sustantivas, adjetivales, adverbiales e interjectivas. Todos estos datos hay que considerarlos con reservas debido a los problemas de catalogación de los que hemos hablado supra. No hay supuestos, por razones obvias, de pronominales, prepositivas y conjuntivas.

\begin{tabular}{|l|c|c|c|c|}
\hline \multicolumn{5}{|c|}{ UF CON NP EN EL DA } \\
\hline GRUPO DE UF & $\begin{array}{c}\text { Antropónimos o } \\
\text { sus derivados }\end{array}$ & $\begin{array}{c}\text { Topónimos o } \\
\text { sus derivados }\end{array}$ & $\begin{array}{c}\text { NM o sus } \\
\text { derivados }\end{array}$ & Total \\
\hline N. $^{\circ}$ DE UNIDADES & 125 & 70 & 14 & 209 \\
\hline
\end{tabular}

TABLA 3.-Número total y por grupos de unidades fraseológicas en el $D A$.

\begin{tabular}{|c|c|c|c|c|c|c|c|c|c|c|}
\hline \multicolumn{11}{|c|}{ TIPOS DE UF CON NP EN EL $D A$} \\
\hline UNIDADES & \multicolumn{3}{|c|}{ Fórmulas } & \multicolumn{3}{|c|}{ Locuciones } & \multicolumn{3}{|c|}{ Frases proverbiales } & \multirow[t]{3}{*}{ Total } \\
\hline & A & $\mathrm{T}$ & NM & A & $\mathrm{T}$ & NM & A & $\mathrm{T}$ & NM & \\
\hline & 12 & 3 & 0 & 102 & 65 & 13 & 11 & 2 & 1 & \\
\hline N. ${ }^{\circ}$ DE UNIDADES & \multicolumn{3}{|c|}{15} & \multicolumn{3}{|c|}{180} & \multicolumn{3}{|c|}{14} & 209 \\
\hline
\end{tabular}

TABLA 4.-Número total y por tipo de unidades fraseológicas con NP en el $D A$.

\subsection{Lexicalización del nombre propio}

Un aspecto general de interés es el hecho de que el NP en la mayor parte de los casos aparece lexicalizado en la UF, aunque hay supuestos en los que este se halla lexicalizado a priori y pasa a formar parte de la UF. Ejemplos de ello serían: martín callado, en Caerle martín callado; samuel, en Tirarse/Echarse un samuel; pancho 'berrinche' en Hacer panchos; ojo de Pancha 'tipo de pan', en Hacerse ojo de Pancha 'hacerse el tonto'; catalina 'piñón dentado que sirve de transmisión de fuerza en una máquina como una noria, un trapiche o una bici- 
cleta', en Írsele la catalina 'perder alguien el juicio'. La lexicalización a priori es la regla, sin embargo, en buena parte de las UF con NM, salvo en Echarle vicks ${ }^{17}$ 'rechazar a alguien', Ponerse las rayobac y Hacerse pireli 'abandonar un lugar con rapidez', la lexicalización se produce a posteriori. Se constata un caso curioso en Venirse las de San Pedro 'saltársele a alguien las lágrimas', donde el determinante representa lágrimas, siendo que lágrimas de San Pedro se registra en el $D L E$ (s. v. lágrima) como expresión coloquial desusada con el sentido de 'piedras o guijarros con que se apedrea a alguien'. Así, parece tratarse de una desviación en el uso de la expresión lexicalizada, dado que para hablar de desautomatización tendría que estar presente la voluntad del hablante, algo de lo que podría dudarse en este caso.

\subsection{Marcas}

Otro dato destacable es la marcación de las UF. El $90 \%$ del total de las unidades presenta marcas sociolingüísticas y pragmáticas. La marca sociolingüística más habitual es pop. (popular), aunque muchas veces viene acompañada de cult. (culto) en situaciones espontáneas de habla. No faltan tampoco las marcas que asocian algunas UF a determinados grupos sociales como juv. (juvenil): ¿Qué Pepes!, Diazepam en vena 'profesor/asignatura aburrida'; delinc. (delincuencial): Dar juan 'matar a alguien', Dar lo mismo Juana que Chana 'matar a alguien'; también vulg. (vulgar): Estar cagao de la Verónica 'andar alguien de muy mala suerte'; o desp. (despectivo): Juan bolas 'persona haragana', Juana tres cocos 'mujer poco femenina'.

\subsection{Las UF con antropónimo en el DA}

Por cuestiones de espacio, y dado que las UF con antropónimo son las más numerosas, nos centraremos en ellas en esta ocasión ${ }^{18}$. Si atendemos a los datos cuantitativos que muestra la tabla 5 , podemos comprobar que son las locuciones el conjunto más numeroso $(102,82 \%)$. Le siguen muy de lejos las fórmulas $(12,9 \%)$ y las frases proverbiales $(11,9 \%)$. Dentro del grupo de las locuciones, sobresalen con mucho las de carácter verbal (61, 60\%).

\footnotetext{
${ }^{17}$ En algunos casos, podría hablarse de la conversión en locución de "meras colocaciones", como en Echarle vicks o Poner(se) las rayobac.

${ }^{18}$ En español, aparte Montoto (1912), citado supra, el autor que más se ha ocupado de este tema es Iglesias Ovejero (1999 y 2015, entre otras muchas publicaciones).
} 


\begin{tabular}{|l|l|c|}
\hline \multicolumn{1}{|c|}{ TIPO } & \multicolumn{1}{|c|}{ SUBTIPOS } & TOTAL \\
\hline \multirow{4}{*}{ FÓRMULAS } & Tratamiento & 0 \\
\cline { 2 - 3 } & Comunicación & 12 \\
\cline { 2 - 3 } & Léxica & 0 \\
\hline \multirow{4}{*}{ LOCUCIONES } & Sustantivas & 17 \\
\cline { 2 - 3 } & Adjetivas & 61 \\
\cline { 2 - 3 } & Verbales & 13 \\
\cline { 2 - 3 } & Adverbiales & 7 \\
\cline { 2 - 3 } & Interjectivas & 11 \\
\cline { 2 - 3 } & Conjuntivas/pronominales/prepositivas & 0 \\
\hline FRASES PROVERBIALES & & \\
\hline
\end{tabular}

TABLA 5.-Número de unidades fraseológicas con antropónimos y sus derivados por subtipos en el $D A$.

En cuanto al origen, estructura y funciones de los nombres propios antroponímicos dentro de las UF, puede establecerse un grupo de nombres propios con denotátum desconocido, en el que:

a) Unas veces estamos solo ante nombres de pila, en general, tradicionales y muy comunes en el mundo hispánico ${ }^{19}$, o algunas de sus formas hipocorísticas, que se ofrecen en la tabla 6 siguiendo el criterio del número de ocurrencias (n. ${ }^{\circ}$ de oc.) en el grupo de UF con antropónimo ${ }^{20}$ (Tabla 6).

\begin{tabular}{|c|c|c|}
\hline N. ${ }^{o}$ DE OC. & NOMBRE DE PILA & HIPOCORÍSTICO \\
\hline 10 & Juan/a & \\
\hline 6 & & Pepe \\
\hline 4 & María & Chana, Pancho/a \\
\hline 2 & Cayetano, Jerónimo, Lucas, Pedro, Samuel & Lacha \\
\hline 1 & $\begin{array}{l}\text { Adela, Ángela, Beatriz, Blas, Camota, Diego, } \\
\text { Feliciana, Flora, Gustavo, Hugo, Inés, Isabel, } \\
\text { Janet, Linda, Magdalena, Manuel, Martín, } \\
\text { Ofelia, Otto, Petra, Sabino, Venancio, Wendy }\end{array}$ & $\begin{array}{l}\text { Cheo, Chuchita, Lolita, } \\
\text { Lucho, Nacho, Pacheco, } \\
\text { Toño }\end{array}$ \\
\hline
\end{tabular}

TABLA 6.-Número de ocurrencias de los nombres de pila e hipocorísticos de las unidades fraseológicas del $D A$.

${ }^{19}$ Nos aparece en dos UF el nombre Verónica, pero no queda claro si la referencia es el personaje religioso o un referente desconocido. Lo más lógico es que se trate de la figura cristiana pero el sentido de los fraseologismos no aporta demasiados datos en este sentido. Vid. García Gallarín (2016: 67-68) en torno a la homonimia que puede darse entre nombres bíblicos y genéricos en expresiones con NP. En principio, incluiremos este nombre en el grupo de los personajes bíblicos y religiosos. Se ha consignado en esta lista Camota, aunque se trate seguramente de un nombre inventado sobre la base de la palabra camote procedente del nahua camotli (vid. DA, s. v. camote).

${ }^{20}$ Se han considerado en el recuento las variantes formales de una misma UF, porque estas variantes, muchas veces, están marcadas dialectalmente y creemos que es interesante dejar constancia de las mismas. 
b) Otras veces - las menos - nos encontramos solo ante las formas de apellido, que se presentan siguiendo el orden alfabético, puesto que estas formas solo aparecen una vez, a saber: Abella, Magoya, Méndez, Moya y Montoto.

Tanto en a) como en b) estos NP pueden aparecer en locuciones verbales transitivas en las que el NP es el objeto directo: Dar juan, Echarse/Tirarse un samuel, Hacer panchos, Llamar a Hugo, Ver a Linda, Vender el sofá de don Otto; otras veces, pueden aparecer en locuciones verbales intransitivas, en fórmulas y frases proverbiales, en las que el NP es el sujeto o el objeto indirecto: María estaba lavando y se le acabó el jabón, Dar lo mismo Chana que Feliciana, Quejarse a Magoya, Quejarse a Montoto; en locuciones adverbiales dentro de sintagmas preposicionales funcionan como término de la preposición: Hasta las de Ofelia, Sin jerónimo de duda o en estructuras comparativas como término de la comparación: Como Juan por su casa; en sintagmas preposicionales pueden complementar a un sustantivo que designa un elemento (objeto/característica/cualidad) perteneciente al NP y que se establece como término de comparación sea esta explícita (lo que es bastante frecuente) o implícita: Quedar como la gata de Abella, Quedar como la chancha de tía Lacha, Ser como la gata de Flora, que llora si se lo meten y si se lo sacan llora. Sobre las estructuras comparativas hablaremos con más detalle más tarde.

c) Además, nos hallamos con formaciones de nombre de pila y apellido siquiera inventado o de nombre de pila acompañado de lexemas pluriverbales determinantes (NP + adj. (part.); NP + sust. (+/- determinación); NP + sust.). En una ocasión, se registra lo que podría constituir una UF onímica (cfr. las onymische Wortverbindungen de Fleischer, 1997 [1982]: 69; Burger, 1998: 47 onymische Phraseologismen): la pascuala 'muerte', un nombre de pila femenino determinado por el artículo. Otras formaciones son: isabel dormida, juan bolas, juan caballo, juan del pueblo, juan sin cielo, juan vainas, juan véndemela, Juana tres cocos, María Palito, martín callado, Nacho Cajón.

También puede establecerse un grupo de UF con antropónimo con denotátum conocido ${ }^{21}$ bien sea porque:

a) Se trata de personajes históricos o legendarios recogidos en una anécdota o relato rastreables siquiera remotos. En ambos casos, puede tratarse de figuras internacionales, panhispánicas o locales: Juárez, La página de Cheo, Maceo, Martínez Campos, las Osorito, Regalado.

b) Son personajes de la literatura popular, de la televisión o del cine, que pueden tener referentes reales o ficticios y que, como en el caso anterior, carác-

${ }^{21}$ De clasificar (y explicar sus motivos) UF con antropónimos se han ocupado, además de Iglesias Ovejero (1984, 1996, 1999 y 2015, entre otros), los siguientes autores (citamos también algunos extranjeros cuyos estudios nos han llamado la atención): Calero Fernández (1992), Häcki Buhofer (1995), Ripollés (1999), Gáll (2008), Barbadillo de la Fuente (2014) y Lončar (2014). 
ter internacional, panhispánico o local: cucarachita Martina, josé miel, Greta, mickey mouse, Tarzán.

c) Constituyen personajes que proceden del mundo religioso cristiano, ya sean personajes bíblicos o santos que aparecen recogidos bajo la forma de hagiónimo. En este grupo sobresalen las UF con el NP Judas: Cristo, Catalina (santa), Jesús, Judas, Magdalena, Sambito (sic), san Alejo, san Crispín, san Juan, san Nicolás, san Pedro, san Quintín, san Roque, Sansón, Verónica.

Como en las UF con denotátum desconocido, el NP puede aparecer en locuciones transitivas como ver a Judas calato 'sentir un dolor muy fuerte y vivo', hacer ver a Judas 'hacer sentir dolor a alguien'; en locuciones intransitivas en las que el NP es el sujeto o el objeto indirecto: llevárselo San Crispín, llevárselo San Quintín; pero, sobre todo, querríamos destacar la presencia del NP en las estructuras comparativas ya sea en locuciones verbales, locuciones adverbiales y en frases proverbiales, como las que siguen:

Entrar y salir como Juan por su casa Estar como la chancha de tía Lacha Estar como la cucarachita Martina Quedar como la gata de Abella

Ser como la gata de Flora, que si se lo meten, grita, y si se lo sacan, llora

Tener más fe que san Roque

Tenerlos más grandes que el caballo de Maceo

Tenerlos más grandes que Maceo

Ver como a Nacho Cajón

Como Juan por su casa

Juan como san Juan a veinticuatro

Dejar como la chancha de tía Lacha

Hacer como Blas [ya comiste ya te vas]
'Tener alguien mucha confianza en un lugar'

'Permanecer encerrado y sin comer'

'Estar indecisa una persona'

'Padecer alguien la frustración de no recibir algo que se esperaba'

'No estar contento con nada y quejarse de todo'

'Creer que algo realmente ocurrirá como se espera, aunque existan en realidad muy pocas probabilidades de que ocurra'

'Ser un hombre muy valiente'

'Mirar a alguien con indiferencia'

'Con entera confianza o libertad'

'De manera muy oportuna o adecuada'

'Indica que alguien está bajo la responsabilidad de otra persona que no le proporciona los medios suficientes para la subsistencia'

'Indica que alguien se marcha de un lugar de forma apresurada'

Estas estructuras que la Nueva gramática (2009: 3430) ha descrito sin mucha fortuna indicando que "introducen en su segundo término ejemplos destacados o representativos de la magnitud que se compara", han sido tratadas con más rigor por Gutiérrez Ordóñez (1997: 64-67), que ha destacado que lo especial de este tipo de expresiones no se halla en su estructura sintáctica, sino en 
las connotaciones culturales de los referentes elegidos como normas de comparación, pues "son seres o magnitudes que, según el saber generalizado, constituyen los representantes superlativos, "el no va más", el colmo de la acción o de la cualidad que entra en juego" (Gutiérrez Ordóñez, 1997: 65). De ahí que las denomine comparaciones prototípicas o elativas (Gutiérrez Ordóñez, 1997: 64). En este mismo sentido se habían mostrado Ortega Ojeda (1990), García-Page (1990) y Mayoral Ramírez (1992: 650), quien indicaba, dando un paso más, que en este tipo de construcciones no hay comparación, sino que se trataría de destacar una cualidad que superaría el máximo grado representado por el modelo denotado por el elemento que sería el núcleo del término subordinado. Es decir, que son siempre expresiones superlativas; más tarde, también, García Benito (1998: 123-124), Rodríguez Ponce (2006), García-Page (2008b: 144) y Ghezzi (2012), entre otros, vuelven a incidir en el grado superlativo de estas estructuras. Ghezzi (2012: 203) da una definición bastante acertada del fenómeno al formular que las comparaciones de intensidad "son unidades fraseológicas que expresan el grado superlativo de una cualidad a través de su comparación con un término prototípico o un estereotipo tangible de tal rango distintivo".

Se ha discutido mucho el estatuto fraseológico de estas comparaciones estereotipadas. Como ha mostrado muy bien García-Page (2008b: 171-172), para el caso del español, el problema de catalogación se debería, sobre todo, a su carácter composicional y a su supuesta falta de idiomaticidad; por ello, para una amplia nómina de investigadores solo serían colocaciones o incluso combinaciones libres en los que únicamente sería locución el sintagma encabezado por como. Otros autores, como Corpas Pastor (1996: 121-122), consideran que en las comparaciones de intensidad se pueden encontrar diversos rasgos que establecerían, en un fuerte grado, su idiomaticidad: 1) su origen, en algunos casos, en un acontecimiento señalado, citas o anécdotas; 2) la presencia de metáforas, metonimias, sinécdoques, etc. que subyacerían a estas construcciones. En este sentido, también habría que añadir los argumentos de Rodríguez Ponce (2006: 532) que reforzarían el carácter idiomático de estas expresiones, a saber: 3) con ellas se atribuye una cualidad a un prototipo, un ser, una cosa, una realidad, que se halla, muchas veces, fosilizado y en el que han podido operar cambios o deformaciones por el uso continuado de la expresión; 4) se aprenden de memoria, están institucionalizadas en el registro coloquial y se comprenden aunque se desconozca el término de la comparación; 5) se orientan normalmente hacia lo negativo y peyorativo. Esta cuestión acerca del carácter más o menos fraseológico de este tipo de construcciones intensivas no solo ha tenido eco en lo que al español se refiere. Como ha mostrado Mellado Blanco (2012), en la fraseología alemana, las comparaciones fijas, como la autora las denomina, junto a los binomios fraseológicos y las estructuras modelo, habían sido postergadas a la periferia del universo fraseológico. Sin embargo, actualmente, y gracias a la 
aplicación de la Gramática de Construcciones en la disciplina fraseológica, ya no se discute su estatus fraseológico. Desde la perspectiva de la Gramática de Construcciones, las comparaciones estereotipadas serían construcciones de naturaleza icónica cuya "estructura morfosintáctica es portadora de un significado intensificador" (Mellado Blanco, 2012).

En cuanto a las estructuras representadas en nuestro subcorpus, el número de comparativas estereotipadas formalmente coincidentes con las comparativas de igualdad de la sintaxis libre es superior al de las que se ajustan al esquema de superioridad. No se ha registrado ninguna construcción de inferioridad ( 0 UF). En este sentido, cabe decir que el hecho de que encontremos, sobre todo, construcciones de igualdad, podría deberse a que ya este esquema implica semánticamente superlatividad. Gutiérrez Ordoñez (1997: 65-66) ha indicado, sin embargo, que ambas estructuras no significan lo mismo; pero se daría una inferencia pragmática que haría que se entendieran como sinónimas. García Benito (1998: 126) ha señalado, por su parte, que también en portugués y francés parece preferirse el esquema comparativo de igualdad; el italiano, en cambio, tendería menos a esta clase de construcciones y sería más habitual el uso del adjetivo sin ningún referente.

Las unidades con aposiopesis del núcleo del primer término de la comparación son las más habituales, lo que tiene ciertas consecuencias de carácter semántico-pragmático. Nos referimos a que la elisión de este elemento estaría marcando la fuerte consolidación cultural del modelo que se ha asociado a la cualidad designada por el elemento nuclear del primer término de la comparación; la consolidación sería tal que, por los principios de relevancia y economía lingüística, ese elemento sería superfluo pues no aportaría ninguna información nueva (García-Page, 1990: 490). Por su parte, en las construcciones de superioridad presentan el mismo número de unidades con el esquema de ser/estar u otro verbo + más + adj./part. + que + sust. (NP). Esto se debe a la imposibilidad de usarlas con aposiopesis. Quizá esa sea otra de las razones de la preferencia del esquema de igualdad frente a otros, puesto que siendo intensivas y relevantes parecen estructuras mucho más económicas.

Otro aspecto que merecería destacarse de nuestro grupo de comparativas ${ }^{22}$ es el referido a los núcleos comparativos (mayoritariamente adjetivos, ya sea explícitos, ya sea elididos). Pero también los referentes nos muestran realidades socioculturales muy interesantes. Estas construcciones intensivas se orientan

${ }^{22}$ También nos encontramos en nuestro conjunto de UF con NP en el $D A$ otras expresiones que no presentan formalmente una estructura comparativa, pero sí podría atribuírseles semánticamente cierto valor comparativo: Ser la mamá de Tarzán 'tener alguien grandes cualidades o ser excelente en su oficio'; Creerse la Greta; Creerse la mamá de Tarzán; Creerse la mona de Tarzán; Creerse la verga de Nerón: en todos los casos, 'creerse alguien muy importante'; Echárselas de Martínez Campos 'echárselas alguien de valentón'. 
claramente, como ocurre en el español general, hacia lo negativo; aunque también algunas se refieren a aspectos positivos como Tenerlos como el caballo / como Масеo. Las UF son actos de habla que imprimen al discurso coloquial (que es donde se adscriben) mayor fuerza ilocutiva y perlocutiva. Como destacó Searle (1986: 39), la modalidad enunciativa no tiene por qué coincidir con el acto. En efecto, en la mayoría de los casos nos encontramos con enunciados aseverativos, cuya fuerza ilocutiva indirecta suele ser una reprobación, el insulto y la recomendación, pero, como señala Pascual López $(2014 ; 22)$, en relación con la correcta interpretación de los refranes, su fuerza ilocutiva proviene del acto de habla que constituye y, por tanto, "de las presuposiciones de los interlocutores que entran en juego en el intercambio comunicativo y que posibilitarán que se logre el efecto perlocutivo que se persigue con dicho acto de habla". Así, si se censura una conducta mediante una comparación fraseológica se está intensificando la negatividad de esa conducta y ello puede llevar a un cambio en la manera de actuar del interlocutor o receptor. Como señala Vigara Tauste (1992), lo que mueve al hablante a usar expresiones estereotipadas es proporcionar el máximo de información y de fuerza ilocutiva de la forma más cómoda y con el menor esfuerzo posible.

El último aspecto que nos gustaría tratar es la inclusión del NP en algunas UF haciendo uso de su potencial fónico, con una finalidad creativa (juegos de palabras o paronomásicos), mnemotécnica o por razones métricas. Como ha destacado Fekete (1984-1985: 842 citado en traducción por Lončar, 2014: 73) en relación conla fraseología croata, estas construcciones con NP, "no tienen ningún argumento histórico ni anecdótico, es decir, carecen de un denotátum concreto, sino que existen en los frasemas solo por razones silábico-métricas". En este mismo sentido, se expresan Ozaeta Gálvez (2003: 555) por lo que respecta al nombre propio en los fraseologismos franceses ligado al "[e]mpleo de procedimientos fónicos como la rima - consonante o asonante-, la aliteración, repetición de fonemas y otros recursos que incrementan la expresividad y muestran una gran eficacia mnemotécnica". Pérez-Salazar (2013: 149), por su parte, ha indicado, al analizar la fraseología del maldecir en el Vocabulario de refranes y frases proverbiales de Correas lo siguiente:

El deseo del mal se proyecta con frecuencia hacia un destinatario inespecífico en tercera persona, $[\ldots]$ pero otras veces adquiere una representación expresiva. Algunos nombres propios o comunes, a menudo realzados con recursos como los apreciativos o el morfema de género (56), y escogidos para rimar, se especializan en esta función: Aguedita, Mariquita, Olalla, Sansón, monacillo, molinillo, ovejita, ave o pájara se emplean (casi siempre como vocativos) para referirse a un individuo cualquiera, presente o ausente.

Hemos constatado que estos recursos se emplean en las fórmulas y frases proverbiales del tipo ¿Entiendes, méndez?, usada para 'preguntar a alguien si ha 
entendido algo' o Cayetano es un buen muchacho, empleada para 'indicar que alguien sabe callarse o ser discreto' o Sabino sabe tanto, que sabe sebo utilizada para 'hacer burla de quien presume demasiado de conocimiento'; tampoco faltan ejemplos de locuciones como Dar lo mismo Chana que Feliciana 'dar lo mismo una cosa que otra'; Ya voy, Toño ${ }^{23}$ 'de ninguna manera' o Por gustavo 'por gusto'.

\section{CONCLUSIONES}

En este trabajo hemos querido ofrecer algunos datos que puedan ser de interés en torno a la fraseología con nombre propio y sus especificidades en el $D A$. Concretamente, nos hemos centrado en el análisis de las UF con antropónimo por ser las más numerosas del grupo de fraseologismos con NP en esta obra lexicográfica, que debe valorarse positivamente por representar la nueva política lexicográfica panhispánica, lo que ha permitido la inclusión de numerosas expresiones de nuestro interés investigador. Hemos de decir, sin embargo, que el tratamiento que se da a la fraseología sigue siendo deficiente. Se emplean las categorías tradicionales - con errores, en algunos casos, como ya hemos indicado supra - sin tener en cuenta la discusión científica que ha girado en torno a ellas. Es más, ni siquiera se considera de manera homogénea lo que se establece en la Nueva gramática en relación con la diferenciación entre las formaciones pluriverbales (compuestos sintagmáticos vs. locuciones). Pero, si volvemos sobre la cuestión de la fraseología con NP en la obra, todavía queda mucho por hacer: por ejemplo, dedicar un estudio global a las UF con nombre propio en el $D A$, esto es, analizar conjuntamente fraseologismos deantroponímicos, detoponímicos y con nombres de marca y/o sus derivados; llevar a cabo una reclasificación de las unidades de acuerdo con las pautas de la moderna Fraseología; realizar un estudio pormenorizado de las referencias culturales y de la trayectoria histórica que subyacen a la lexicalización del NP, ya se dé esta en la UF o haya precedido a su inclusión en la expresión idiomática. Algunos de estos trabajos ya los hemos efectuado, pero, por razón de espacio, no hemos podido presentar sus resultados en esta ocasión. En otros seguimos trabajando con la esperanza de poder exponerles nuevos resultados en el futuro.

\footnotetext{
${ }^{23}$ Esta expresión se incluye entre las locuciones adverbiales en el DA (s. v. ir), aunque nosotros dudamos de esta adscripción: a nuestro juicio, por su estructura se trata de una fórmula.
} 


\section{BIBLIOGRAFÍA}

Almansa Ibáñez, Soraya (2014): "Repercusión del Diccionario de americanismos en el aula de español como segunda lengua", en Narciso M. Contreras Izquierdo (ed.), La enseñanza del español como LE/L2 en el siglo XXI, Madrid, Asociación para la Enseñanza del Español como Lengua Extranjera, pp. 35-45.

Alvar Ezquerra, Manuel (2003): "Diccionario y gramática", en Manuel Alvar Ezquerra, Lexicografía descriptiva, Barcelona, Vox-Biblograf, pp. 87-143.

Aranda Gutiérrez, Cristina (2010): "La lexicalización y rentabilidad de los nombres de marca como bases léxicas", en Joaquín Sueiro Justel (coord.), III Congreso internacional de lingüística hispánica (CILHIS). Novos investigadores en linguas e lingüística: Actas, Lugo, Editorial Axac, pp. 11-21.

Asociación de Academias de la Lengua Española (2010): Diccionario de americanismos, Lima, Santillana.

Bajo Pérez, Elena (2008): El nombre propio en español, Madrid, Arco/Libros.

Bally, Charles (1944 [1932]): Linguistique générale et linguistique française, Berne, A. Francke.

Barbadillo de la Fuente, M. ${ }^{a}$ Teresa (2014): "Onomástica personal del Vocabulario de refranes y frases proverbiales de Gonzalo Correas", Paremia, 23, pp. 57-68.

Batista Rodríguez, José Juan y Dolores García Padrón (2018): "Nombres propios en fraseologismos de Góngora y Quevedo: función semántica e idiomaticidad”, en María Teresa Echenique Elizondo, Angela Schrott y Francisco Pla (eds.), Cómo se hacen las unidades fraseológicas: continuidad y renovación en la diacronía del espacio castellano, Berlin, Peter Lang, pp. 71-109.

Bauer, Laurie (1983): English Word Formation, Cambridge, Cambridge University Press.

Blasco Mateo, Esther (2002): "La lexicalización y las colocaciones", LEA. Lingüística Española Actual, 24 (1), pp. 35-62.

Bosque, Ignacio (1982): "Más allá de la lexicalización”, Boletín de la Real Academia Española, Tomo 62, Cuaderno 225, pp. 103-158.

Bosque, Ignacio (2001): "Sobre el concepto de ‘colocación' y sus límites”, LEA. Lingüística Española Actual XXIII/ 1, pp. 9-40.

Bravo García, Eva (2015): "El diccionario de americanismos. Una aproximación formal al léxico del español de América", RiCOGNIZIONE. Rivista de lingue, letterature e culture moderne, 3 (II), pp. 177-185.

Brinton, Laurel J. (2000): The Structure of Modern English: a Linguistic Introduction, Amsterdam, Philadelphia, John Benjamins.

Brinton, Laurel J. y Elizabeth C. Traugott (2005): Lexicalization and Language Change. Cambridge, Cambridge University Press.

Buenafuentes de la Mata, Cristina (2007): Procesos de gramaticalización y lexicalización en la formación de compuestos en español, Tesis doctoral, Bellaterra, Universitat Autònoma de Barcelona.

Buenafuentes de la Mata, Cristina y Carlos Sánchez Lancis (2012): "Procesos de gramaticalización y lexicalización a la luz de los corpus académicos", en Tomás Jiménez Juliá, Belén López Meirama, Victoria Vázquez Rozas y Alexandre Veiga (eds.), Cum corde et in nova grammatica. Estudios ofrecidos a Guillermo Rojo, Santiago de Compostela, Universidad de Santiago de Compostela, pp. 153-165.

Burger, Harald (1998): Phraseologie. Eine Einführung am Beispiel des Deutschen, Berlin, Erich Schmidt Verlag.

Bustos Gisbert, Eugenio (1986): La composición nominal en español, Salamanca, Universidad de Salamanca.

Calero Fernández, M. a Ángeles (1992): "Nombres parlantes femeninos en la onomástica paremiológica española", en Manuel Ariza et alii (eds.): Actas del II Congreso Internacional de Historia de la Lengua Española, Madrid, Arco/Libros, tomo II, pp. 907-917. 
Casares, Julio (1992 [1950]): Introducción a la lexicografía moderna, Madrid, CSIC.

Castillo Carballo, M. ${ }^{a}$ Auxiliadora (1998a): “¿Compuestos o locuciones?”, en Manuel Alvar Ezquerra y Gloria Corpas Pastor (coords.), Diccionarios, frases, palabras, Málaga, Universidad de Málaga, pp. 147-155.

Castillo Carballo, M. ${ }^{a}$ Auxiliadora (1998b): "El término 'colocación' en la lingüística actual", LEA, Lingüística Española Actual XX/1, pp. 41-54.

Castillo Carballo, M. a Auxiliadora (2001): "Tratamiento de las unidades pluriverbales en dos diccionarios de español: DRAE y DUE”, en Stefan Ruhstaller y Josefina Prado Aragonés (eds.), Tendencias en la investigación lexicográfica del español, Huelva, Universidad de Huelva, pp. 357-364.

Castillo Carballo, M. ${ }^{a}$ Auxiliadora (2020): "Problemas de catalogación lexicográfica en las llamadas 'combinaciones estables'", en Esteban Montoro del Arco, Carsten Sinner y Encarnación Tabares Plasencia (eds.), Clases y categorías en la fraseología del español, Leipzig, Universitätsverlag (en prensa).

Castro Zapata, Isabel M. a (2013): “«Miope de razón, clarividente de intuición». El participio de presente en la formación de algunos compuestos léxicos en español", en Emili Casanova y Cesáreo Calvo Rigual (coords.), Actas del XXVI Congreso Internacional de Lingüística y de Filología Románicas, vol. 4. Berlin, De Gruyter, pp. 65-78.

Company Company, Concepción (2003): "La gramaticalización en la historia del español", $M e$ dievalia, 35, pp. 3-61.

Corpas Pastor (1996): Manual de Fraseología española, Madrid, Gredos.

Déniz Hernández, Margarita (2001): "El tratamiento de las expresiones fijas en los diccionarios modernos de español", en Stefan Ruhstaller y Josefina Prado Aragonés (eds.), Tendencias en la investigación lexicográfica del español, Huelva, Universidad de Huelva, pp. 377-386.

Echenique Elizondo, María Teresa (2010): "Las unidades fraseológicas en la historia del español", en Actas del XVI Congreso de la Asociación Internacional de Hispanistas: Nuevos caminos del hispanismo (París, 9-13 de julio de 2007), Centro Virtual Cervantes, <https:// cvc.cervantes.es/literatura/aih/pdf/16/aih_16_2_013.pdf >.

Elvira, Javier (2006): “Aproximación al concepto de lexicalización”, en Javier Rodríguez Molina y Daniel Moisés Sáez Rivera (coords.), Diacronía, lengua española y lingüística: Actas del IV Congreso Nacional de la Asociación de Jóvenes Investigadores de Historiografía e Historia de la Lengua Española, Madrid, pp. 21-42.

Elvira, Javier (2012): "Gramaticalización y lexicalización: ¿opuestos, paralelos, convergentes?", en Emilio Montero Cartelle y Carmen Manzano Rovira (coords.), Actas del VIII Congreso Internacional de Historia de la Lengua Española, Santiago de Compostela, vol. 1, pp. 315-326.

Elvira, Javier (2015): Lingüística histórica y cambio gramatical, Madrid, Síntesis.

Faitelson-Weiser, Silvia (1980): Les suffixes quantificateurs de l'espagnol, Paris, Éditions Hispaniques.

Fekete, Egon (1984-1985): “Antroponimski elementi u srpskohrvatskim frazeolokim ignomskim obrtima”, ZbFL, Zbornik za filologiju i ling-vistiku 27-28, pp. 835-843.

Fleischer, Wolfgang (1997 [1982]): Phraseologie der deutschen Gegenwartssprache, Tübingen, Niemeyer.

Földes, Csaba (1984-1985): "Eigennamen in deutschen phraseologischen Redewendungen", Muttersprache. Zeitschrift zur Pflege und Erforschung der deutschen Sprache, 95, pp. 174-180.

Gáll, Kinga (2008): "Namen in Phraseologismen", en Temeswarer Beiträge zur Germanistik, Timişoara, Mirton Verlag, tomo 6, pp. 59-74.

García Benito, Ana Belén (1998): "Comparaciones fraseológicas del español y del portugués: estudio contrástico", Interlingüística, 9, pp. 123-128.

García Gallarín, Consuelo (2016): "La lexicalización de los nombres bíblicos en la historia del español”, Hamsa. Journal of Judaic and Islamic Studies, 3, pp. 62-77. 
García Gallarín, Consuelo (2017): "Deonomástica hispánica. Un acercamiento metodológico", Bulletin of Spanish Studies, 94, 10, pp. 1045-1062, <https://doi.org/10.3828/bhs.2017.64>.

García Gallarín, Consuelo y Celeste García Gallarín (1997): Deonomástica hispánica. Vocabulario científico, humanístico y jergal, Madrid, Editorial Complutense.

García Padrón, Dolores (2016): "Aspectos lingüísticos-culturales que intervienen en la formación de epónimos en español”, en Ana Díaz Galán y Marcial Morera (eds.), Estudios en Memoria de Franz Bopp y Ferdinand de Saussure, Berlin, Peter Lang, pp. 93-103.

García Padrón, Dolores (2019): "Las expresiones fijas con nombre propio en el diccionario general", en Dolores García Padrón (coord.), Desarrollos del nombre propio en español: adjetivos de relación y lexicalizaciones, Madrid, Arco/Libros, pp. 137-166.

García Padrón, Dolores y José Juan Batista Rodríguez (2010a): "Reflexiones sobre aspectos semánticos y sintácticos de las colocaciones nominales", en Dolores García Padrón y María del Carmen Fumero Pérez (eds.), Tendencias en lingüística general y aplicada, Frankfurt am Main Peter Lang, pp. 127-135.

García Padrón, Dolores y José Juan Batista Rodríguez (2010b): "Las combinaciones nominales en español: aspectos sintácticos, semántico-denotativos y terminológicos", LEA. Lingüística Española Actual, XXXII/2, pp. 197-222.

García Padrón, Dolores y José Juan Batista Rodríguez (2018): “Adjetivos deantroponímicos con el sufijo -ano en español”, Estudios de Lingüística del Español, 39, pp. 161-179.

García-Page, Mario (1990): "Frases elativas", en María Ángeles Álvarez Martínez (ed.), Actas del Congreso de la Sociedad Española de Lingüística: XX Aniversario (Tenerife, 2-6 de abril de 1990), Madrid, Gredos, pp. 485-496.

García-Page, Mario (2008a): Introducción a la fraseología española. Estudio de las locuciones, Barcelona, Anthropos.

García-Page, Mario (2008b): "La comparativa de intensidad: la función del estereotipo", Verba, 38, pp. $143-178$.

García-Page, Mario (2012): “Pourquoi perrito caliente n'est pas la meme chose que patata caliente? Du composé á la locution nominale", en Xavier Blanco Escoda, Sandrine Fuentes Crespo y Salah Mejri (coords.), Les locutions nominales en langue générale, Barcelona, Universitat Autònoma de Barcelona, pp. 79-108.

García-Page, Mario (2013): "En torno a la locución en el DRAE", Bulletin of Hispanic Studies, 90 (3), pp. 251-260, <https://doi.org/10.3828/bhs.2013.17>.

Ghezzi, Maddalena (2012): "Creación de una base de datos para el estudio de las comparaciones estereotipadas y su explotación en la enseñanza de ELE”, en María Isabel González Rey (ed.), Unidades fraseológicas y TIC, Madrid, Instituto Cervantes (Centro Virtual Cervantes), pp. 203-216.

Gutiérrez Ordóñez, Salvador (1997): Estructuras Comparativas, Madrid, Arco Libros.

Häcki Buhofer, Annelies (1995): "Namen in phraseologischen Wendungen", en Ernst Eichler, Gerold Hilty, Heinrich Löffler, Hugo Steger y Ladislav Zgusta (eds.) Namenforschung / Name Studies / Les noms propres, Berlin/New York, De Gruyter, pp. 493-498.

Herrero Ruiz de Loizaga, Francisco Javier (2002): "El paso de los nombres propios a comunes en español”, LEA. Lingüística Española Actual, XXIV/2, pp. 225-252.

Iglesias Ovejero, Ángel (1984): "Figuración proverbial y nivelación en los nombres propios del refranero antiguo: figuras vulgarizadas del registro culto", Criticón, 28, pp. 5-95.

Iglesias Ovejero, Ángel (1991): "Nombres propios: Para una tentativa de clasificación", en Antoni Badia i Margarit (ed.), Dictionnaire historique des noms de famille romans. Actes del III Col-loqui (Barcelona, 19-21 juny 1989), Tübingen, Niemeyer, pp. 227-228.

Iglesias Ovejero, Ángel (1996): "Nombres de personajes y figuras tradicionales o tradicionalizadas en la Recopilación (1554) de Diego Sánchez de Badajoz", Criticón, 66-67, pp. 57-74.

Iglesias Ovejero, Ángel (1999): "La proverbialidad del nombre propio y las figuras del refranero", Paremia, 8, pp. 279-288. 
Iglesias Ovejero, Ángel (2015): "El árbol paremiológico de Pedro", Anuari de Filologia. Estudis de lingüística, 5, pp. 79-108.

Koike, Kazumi (2005): "Colocaciones complejas en el español actual”, en Ramón Almela Pérez, Gerd Wotjak, Gerd y Estanislao Ramón Trives (coords.), Fraseología contrastiva: con ejemplos tomados del alemán, español, frances e italiano, Murcia, Universidad de Murcia, $169-184$.

Langendonck, Willy van (2007a): "Proper Names as the Prototypical Nominal Category", Names, 55, pp. 437-444, <https://doi.org/10.1179/nam.2007.55.4.437>.

Langendonck, Willy van (2007b): Theory and Typology of Proper Names, Berlin/New York, De Gruyter.

Lehmann, Christian (2003): "New reflections on grammaticalization and lexicalization", en Ilse Wischer y Gabriele Diewald (eds.), New reflections on grammaticalization, Amsterdam, John Benjamins, pp. 1-18.

Leiva Rojo, Jorge (2015): "Fraseografía y lingüística de corpus: sobre el tratamiento de locuciones verbales en la nueva edición del Diccionario de la lengua española", en Gloria Corpas Pastor (ed.), Computerised and corpus-based approaches to phraseology: Monolingual and multilingual perspectives (full papers), Geneva, Tradulex, pp. 419-427.

Lipka, Leonhard (1983): "A multi-Level Approach to Word-Formation: Complex Lexemes and Word Semantics", en Shirô Hattori y Kazuko Inoue (eds.), Proceedings of the XIIIth International Congress of Linguistics. Tokio1982, Tokio/The Hague, CIPL, pp. 926-928.

Lisyová, Olga (2005): "La derivación adjetival a partir de los nombres propios", Moenia, 11, pp. 249-268.

Lončar, Ivana (2014): "Nombres propios de la fraseología croata", Language Design, 16, pp. 63-80.

Lyons, John (1977): Semantics, Cambridge, Cambridge University Press.

Malá, Milada (2014): "Algunas consideraciones acerca de la morfología de los adjetivos deonomásticos de persona", en Miroslava Aurová, María José Santiago Gutiérrez, Jana Pešková y Josef Prokop (eds.), Al pie de la(s) letra(s), Ėeské Budijovice, Universidad de Bohemia Meridional, <http://alpiedelasletras.sweb.cz/mala_milada_adjetivos_deonomasticos.pdf $>$.

Mayoral Ramírez, José Antonio (1992): "Sobre construcciones comparativas en el lenguaje poético de los siglos XVI y XVII", en José Antonio Bartol Hernández, Javier de Santiago Güervós y Juan Felipe García Santos (eds.), Estudios filológicos en homenaje a Eugenio de Bustos Tovar, Salamanca, Universidad de Salamanca, pp. 641-656.

Mazzocchi, Giuseppe (2015): "El Diccionario de Americanismos (DA) de la Asociación de Academias de la Lengua Española (ASALE)", Cuadernos AISPI, 6, pp. 53-74.

Meillet, Antoine (1912): "L'évolution des formes grammaticales", Linguistique Historique et Linguistique Générale, Paris, Champion, pp. 130-148.

Mellado Blanco, Carmen (2012): "Las comparaciones fijas en alemán y español: algunos apuntes contrastivos en torno a la imagen", Linred: Lingüística en la Red, 10, <https://ebuah.uah.es/ dspace/handle/10017/24018>.

Migliorini, Bruno (1968[1927]): Dal nome proprio al nome comune, Firenze, Olschki.

Montoro del Arco, Esteban Tomás (2006), Teoría fraseológica de las locuciones particulares. Las locuciones prepositivas, conjuntivas y marcadoras en español, Frankfurt, Peter Lang.

Montoro del Arco, Esteban Tomás (2008): "Relaciones entre Morfología y Fraseología: las formaciones nominales pluriverbales", en Ramón Almela Pérez y Esteban Tomás Montoro del Arco (eds.), Neologismo y morfología, Murcia, Universidad de Murcia, pp. 121-146.

Montoro del Arco, Esteban Tomás (2017): "La intersección entre composición y fraseología: apuntes historiográficos", en M. ${ }^{a}$ Teresa Echenique Elizondo y Francisco Pla Colomer (eds.), La fraseología a través de la historia de la lengua española y su historiografía, Valencia, Tirant lo Blanch, pp. 213-245.

Montoto, Luis (1912): Personajes, personas y personillas que corren por las tierras de ambas Castillas, Sevilla, Librería de San José, 3 vols. 
Moreno Cabrera, Juan Carlos (1998): "On the relationships between grammaticalization and lexicalization", en Anna Giacalone Ramat y Paul J. Hopper (eds.), The Limits of grammaticalization, Amsterdam/Philadelphia, John Benjamins, pp. 209-227.

Moreno Cabrera, Juan Carlos (2013): Cuestiones clave de la lingüística, Madrid, Síntesis.

Morera, Marcial (2015): "El gentilicio en español: tipos, significaciones y sentidos", en Marcial Morera (coord.), El gentilicio en español: aspectos teóricos y prácticos, Madrid, Arco/Libros, pp. 11-96.

Morera, Marcial (2017a): Cortesía, apodos e hipocorísticos en español: fundamentos lingüísticos, Madrid, Arco Libros

Morera, Marcial (2017b): "La lexicalización del nombre propio como fuente de raíces léxicas", LEA, Lingüística Española Actual, XXXIX (1), pp. 85-101.

Nazarov, Kambarali y Álvaro Alfredo Bragança (2014): "Der onymische Name als Spracheinheit und deonymische Phraseologismen im Vergleich", Caderno de Letras, 22, pp. 1-15.

Ortega Ojeda, Gonzalo Damián (1990): "Comparaciones estereotipadas y superlatividad", en María Ángeles Álvarez Martínez (ed.), Actas del Congreso de la Sociedad Española de Lingüística: XX Aniversario (Tenerife, 2-6 de abril de 1990), Madrid, Gredos, pp. 729-737.

Ozaeta Gálvez, María Rosario (2003): "Los antropónimos en las unidades fraseológicas de la lengua francesa y su equivalencia en español", en Ignacio Iñarrea Las Heras y María Jesús Salinero Cascante (coords.), El texto como encrucijada: estudios franceses y francófonos, vol. II, Logroño, Universidad de La Rioja, pp. 553-564.

Pascual López, Xavier (2014): "El refrán como estrategia comunicativa: (des)codificación del sentido y función pragmático-discursiva [Proverbs as a Communication Strategy: (De)codification of Meaning and Pragmatic-Discursive Function], Studia Romanica Posnaniensia XLI/1, pp. 17-30.

Pérez-Salazar, Carmela (2013): "Fraseología del maldecir en el Vocabulario de refranes y frases proverbiales de Gonzalo de Correas", RFULL, Revista de la Facultad de Filología de la Universidad de La Laguna 31, pp. 141-158.

Pérez Vigaray, Juan Manuel (1996): "Locuciones y compuestos nominales: aportaciones de Julio Casares al estudio de la formación de palabras", Philologica canariensia, 2/3, pp. 305-319.

Pérez Vigaray, Juan Manuel y José Juan Batista Rodríguez (2005): “Composición nominal y fraseología”, en Ramón Almela Pérez, Gerd Wotjak y Estanislao Ramón Trives (coords.), Fraseología contrastiva: con ejemplos tomados del alemán, español, frances e italiano, Murcia, Universidad de Murcia, pp. 81-90.

Real Academia Española / Asociación de Academias de la Lengua Española (2009): Nueva gramática de la lengua española. Morfología y Sintaxis, Madrid, Espasa, 2 vols.

Reinhardt, Jan (2010): "El proyecto de un Deonomasticon iberoromanicum (DIR)", Zeitschrift für Romanische Philologie, 126, 4, pp. 593-601, <https://doi.org/10.1515/zrph.2010.054>.

Ripollés, Roser (1999): “Onomástica i Paremiologia. Els antropónims", Paremia, 8, pp. 449-452.

Rodríguez Ponce, María Isabel (2006): "Las comparaciones estereotipadas y su aprovechamiento en la enseñanza del español como lengua extranjera", en La competencia pragmática y la enseñanza del español como lengua extranjera, Oviedo, Servicio de Publicaciones de la Universidad de Oviedo, pp. 528-537.

Ruiz Gurillo, Leonor (2000): "Cómo integrar la fraseología en los diccionarios monolingües", en Gloria Corpas Pastor (ed.), Las lenguas de Europa: estudios de fraseología, fraseografía y traducción, Granada, Comares, pp. 261-174.

Ruiz Gurillo, Leonor (2002): “Compuestos, colocaciones, locuciones: intento de delimitación”, en Aleixandre Veiga, Miguel González Pereira y Monserrat Souto Gómez (eds.), Léxico y Gramática, Lugo, Tris Tram, pp. 327-339.

Schweickard, Wolfgang (1992): Deonomastik. Ableitungen auf der Basis von Eigennamen im Französischen (unter vergleichender Berücksichtigung des Italienischen, Rumanischen und Spanischen), Tübingen, De Gruyter. 
Schweickard, Wolfgang (1995): "Morphologie del Namen: Ableitungenauf der Basis von Eigennamen", en Ernst Eichler et alii (eds.), Namenforschungen / Name Studies / Les noms propres, Berlin/New York, De Gruyter, tomo I, pp. 431-435.

Searle, John (1986): Actos de habla, Madrid, Cátedra.

Sinner, Carsten y Encarnación Tabares Plasencia (2016): "El problema de las variantes fraseológicas desde la perspectiva de la lingüística de variedades", RLA: Revista de lingüística teórica y aplicada, 54 (2) (II Sem.), pp. 13-41, <https://doi.org/10.4067/s0718-48832016000200002>.

Talmy, Leonard (1985): "Lexicalization patterns: semantic structures in lexical forms", en Timothy Shopen (ed.), Language typology and syntactic descriptions, Cambridge, Cambridge University Press, pp. 57-149.

Tristá Pérez, Ana María (1998): "La fraseología y la fraseografía”, en Gerd Wotjak (ed.), Estudios de fraseología y fraseografía del español actual, Frankfurt am Main/Madrid, Vervuert/ Iberoamericana, pp. 297-305.

Val Álvaro, Francisco (1999): "La composición”, en Ignacio Bosque y Violeta Demonte (coords.), Gramática descriptiva de la lengua española, Madrid, Espasa Calpe, pp. 4557-4841.

Vigara Tauste, Ana María (1992): Morfosintaxis del español coloquial. Esbozo estilístico, Madrid, Gredos.

Wotjak, Barbara (1998): "Unidades fraseológicas en un diccionario de aprendizaje de alemán como lengua extranjera", en Gerd Wotjak (ed.), Estudios de fraseología y fraseografía del español actual, Frankfurt am Main/Madrid, Vervuert/Iberoamericana, pp. 343-363.

Wotjak, Barbara (2005): "Fórmulas rutinarias en los diccionarios didácticos", en Juan de Dios Luque Durán y Antonio Pamies Bertrán (eds.), La creatividad en el lenguaje: colocaciones idiomáticas y fraseología, Granada, Método Ediciones, pp. 331-350.

Wotjak, Barbara y Antje Heine (2005): "Überlegungen zur Abgrenzung und Beschreibung verbonominaler Wortverbindungen (Wortidiome, Funktionsverbgefüge, Kollokationen): Vorleistungen für die (lerner-)lexikographische Praxis", Deutsch als Fremdsprache, 3, pp.143-153.

Wotjak, Gerd (1998a): "Reflexiones acerca de construcciones verbo-nominales funcionales", en Gerd Wotjak (ed.), Estudios de fraseología y fraseografía del español actual, Frankfurt am Main/Madrid, Vervuert/Iberoamericana, pp. 257-280.

Wotjak, Gerd (1998b): “¿Cómo tratar las UFS en el diccionario?”, en Gerd Wotjak (ed.), Estudios de fraseología y fraseografía del español actual, Frankfurt am Main/Madrid, Vervuert/ Iberoamericana, pp. 307-322.

Zuluaga, Alberto (2002): "Los 'enlaces frecuentes' de María Moliner. Observaciones sobre las llamadas colocaciones”, LEA. Lingüística Española Actual, XXIV/1, pp. 97-114.

Fecha de recepción: 6 de agosto de 2018

Fecha de aceptación: 17 de octubre de 2018 